\title{
"Você sabe como é, eles não estão acostumados com antropólogos!": uma análise etnográfica da formação de professores
}

Rodrigo Rosistolato*

\section{Resumo}

A escola passou, na segunda metade da década de 1990, por uma mudança significativa em suas funções sociais. A partir dos Parâmetros Curriculares Nacionais (PCN), ela foi convocada a contribuir com a socialização afetiva e sexual de adolescentes e jovens, via projetos de orientação sexual escolar. Entendia-se que a escola não deveria educar para a sexualidade, mas, sim, orientar. Essa nova demanda proporcionou uma série de debates sobre a escola e o que se deve fazer nela, além de ter sido o passo inicial para a configuração de cursos de formação de professores para o trabalho com orientação sexual na escola. Este artigo apresenta reflexões com base em pesquisas etnográficas realizadas em cursos de formação de professores e em salas de aula onde se desenvolviam projetos de orientação sexual na cidade do Rio de Janeiro. Descrevem-se as classificações relacionadas à sexualidade, à diversidade sexual e ao lugar da escola nesse debate.

\section{Palavras-chave}

Antropologia; gênero; diversidade; sexualidade; orientação sexual.
* Professor da Faculdade de Educação da Universidade Federal do Rio de Janeiro (UFRJ), Brasil. rosistolato@yahoo.com.br. 


\title{
"You know, they are not used to anthropologists!": an ethnographic analysis of teacher training programs
}

\begin{abstract}
The school system in Brazil, in the middle of 1990's, went through a significant change in its social functions. As from the publication of the National Curricular Parameters (PCN's), the school was invited to contribute to an affective and sexual socialization among teenagers and youngsters through sexual orientation projects. It was understood that the school shouldn't have sexual education, but 'sexual orientation'. This new demand promoted a lot of debates about school and what should be done in it, besides being the first step for the configuration of teachers' training programs to prepare them for the work with sexual orientation at schools. This article presents reflections based on ethnographic research carried out in teachers' training courses and in classrooms where sexual orientation projects were being developed in Rio de Janeiro. It also describes the classification related to sexuality, sexual diversity and where the school is placed in this debate.
\end{abstract}

Key words

anthropology; gender; diversity; sexuality and sexual orientation. 


\section{Introdução}

A afirmação que serve de título a este artigo foi feita por uma professora que ocupava um cargo de confiança na Secretaria Municipal de Educação do Rio de Janeiro. Estávamos ao telefone, discutindo minha participação em um curso de formação de professores para o desenvolvimento de projetos de orientação sexual em escolas do Ensino Fundamental. Não nos conhecíamos pessoalmente, e a conversa tinha o objetivo de testar a adequação de meu perfil profissional à proposta do curso.

0 telefonema teve 40 minutos de duração. Começou com uma fala em que a professora expôs a principal dúvida que a fizera entrar em contato pessoalmente. Ela disse:

Olha, você conhece mesmo este tema? Estou perguntando porque nós sempre convidamos psicólogos e pedagogos. Nunca tivemos nenhum antropólogo aqui. Só estou ligando porque foi o JP ${ }^{1}$ que indicou seu nome, e eu não tinha como deixar de aceitar uma indicação dele.

Minha resposta foi sim. Disse que conhecia Antropologia, estava estudando o desenvolvimento de projetos de orientação sexual em escolas e propunha um diálogo sobre a circulação de conceitos e teorias presentes em políticas públicas. Ainda tentei dizer que iria analisar o ponto de vista de professores e gestores sobre as demandas que lhes são apresentadas pelo poder público. Só tentei, porque ela me interrompeu e disse: "Não é isso que estou perguntando. Isso não vem ao caso. Preciso saber se você sabe fazer formação de professores com Antropologia, só isso! Você sabe?".

A segunda pergunta fez com que eu percebesse que me encontrava em uma situação limite. Era necessário dar uma resposta simples para uma pergunta complexa. JP tinha me convidado para fazer uma palestra sobre minha pesquisa para um grupo de professores da Secretaria Municipal de Educação. Durante o telefonema, percebi que as intenções da interlocutora eram diferentes. Ela não queria que eu fizesse uma palestra ou seminário. Ao contrário, desejava que eu organizasse um dos encontros do curso de capacitação e, em suas palavras, "formasse os professores com Antropologia”. Ao mesmo tempo, ela não entendia por que JP indicara um antropólogo, e só estava telefonando porque não se sentia à vontade para recusar uma indicação feita por ele.

Aquele telefonema era resultado de um lon1. JP era um de meus principais informantes. 
go processo de inserção no campo de pesquisa, que poderia ficar prejudicada, caso minha reputação fosse desconstruída. Desnecessário dizer que esses aspectos de minha reputação foram construídos à revelia, porque nunca me havia apresentado como um formador de professores. Ao contrário, sempre havia dito que meus objetivos estavam localizados na pesquisa, mas não funcionou! Os "nativos" com os quais interagia construíram uma representação sobre o antropólogo que com eles convivia, e o personagem ganhou existência própria, independente do ator que o representava.

A situação limite precisava de solução, e eu não poderia tentar outra resposta genérica. Na sequência da conversa, eu disse que sim. Que sabia fazer formação de professores com Antropologia e acreditava que minha participação no evento seria bastante produtiva, porque eu ofereceria um olhar diferente daquele apresentado por pedagogos e psicólogos. A professora deu-se por satisfeita e encerrou a ligação, dizendo que outra pessoa telefonaria para acertar os detalhes do evento. Pediu desculpas por ter sido tão enfática e comentou que suas preocupações eram justificáveis, porque os professores, "você sabe como é, eles não estão acostumados com antropólogos!".

0 relato dessa conversa pontua as questões que orientam este artigo. Farei a descrição de uma situação de pesquisa em que o investigador foi convidado a transcender as tênues fronteiras entre observação e ação. Enfatizarei as tensões presentes nos processos sucessivos de conhecimento e reconhecimento vividos pelo antropólogo e por "seus nativos". Pretendo argumentar que as interações desenvolvidas durante o trabalho de campo em escolas permitem que o investigador seja alvo de classificações que o enquadram em identidades convergentes com a vida escolar. Demonstrarei como o trabalho de campo para uma pesquisa sobre orientação sexual fez com que eu transitasse do anonimato do pesquisador para o reconhecimento no grupo dos orientadores sexuais. Também apresentarei os resultados desse trabalho de campo ${ }^{2}$ - descreverei as leituras dos conceitos de gênero, sexualidade e diversidade presentes no desenvolvimento de projetos de orientação sexual na escola.

\section{Antropologia na escola}

O debate sobre o trabalho antropológico em Educação tem recebido contribuições que indicam alguns consensos. Neusa

2. 0 material - composto por observações e entrevistas em profundidade - foi produzido e sistematizado durante os quatro anos em que permaneci no campo.
Gusmão (2008) aponta que Antropologia e Educação constituem um “campo tensional”, por- 
que estabelecido em espaços onde a análise interage com os aspectos políticos relacionados às expectativas de formação e construção de pessoas que orientam os sistemas educacionais.

Essa reflexão converge com aquela realizada por Tania Dauster (1997). A autora afirma que a Antropologia da Educação enfrenta obstáculos teóricos, metodológicos e políticos, porque a construção da diferença, como objeto de análise, dialoga, obrigatoriamente, com a construção da igualdade como conceito norteador de políticas educacionais.

Ao mesmo tempo, Antropologia e Educação são apresentadas como duas ciências diferentes, mas em diálogo (Rocha; Tosta, 2009). 0 objeto da Antropologia da Educação estaria na confluência entre as duas ciências, formando um campo interdisciplinar. Há dificuldades teóricas e epistemológicas implícitas na ideia de interdisciplinaridade, o que amplia os desafios presentes na composição dos objetos e na realização de pesquisas que visem a uma abordagem propriamente antropológica da Educação.

Nesse sentido, qual seria a diferença entre a Antropologia dos fenômenos educacionais e os estudos em Educação e/ou Sociologia da Educação? Se considerarmos que a marca da Antropologia é a etnografia, podemos propor que a distinção se daria pelo uso intensivo desta técnica repleta de método. Quais seriam as implicações de uma etnografia na escola?

Quando elegemos a escola como objeto de análise, enfrentamos "nativos" diferentes daqueles analisados por Malinowski (1980). O exercício de imaginar-se em uma ilha distante ganha outros significados nesses contextos em que o "outro" pode ser, com certa frequência, próximo àquele que realiza a pesquisa. A escola, como instituição, e os agentes presentes nesse contexto são familiares para os pesquisadores. A formação escolar, como experiência englobante, é compartilhada por todos que decidem trabalhar com Antropologia e Educação. Assim, de certa forma, todos são "antropólogos nativos".

O problema da familiaridade pode ser minimizado com a utilização dos caminhos propostos por Gilberto Velho e Karina Kuschnir (2003). Desde a década de 1980, dispomos de reflexão metodológica para a realização do exercício de transformação do familiar em exótico. A Antropologia na escola consolida-se como um exercício de estranhamento de um espaço, inicialmente, familiar. Porém, como pretendo demonstrar, a construção do lugar do antropólogo em campo, quando o campo é a escola, não se esgota com o exercício de estranhamento proposto. 
Durante minhas tentativas de inserção no Sistema Municipal de Educação do Rio de Janeiro, ouvi, sucessivamente, falas de resistência à presença de sociólogos e antropólogos nos contextos escolares. Os debates giravam em torno de uma questão inquietante: o que você vai fazer aqui (na escola)?

Tal questão distancia o antropólogo que observa o campo educacional daquele que analisa uma cultura “exótica”. Diferente do processo vivido por Anthony Seeger (1980), o antropólogo na escola não é uma criança no mundo. Seeger (1980), no relato de sua experiência com os Suyá, realiza uma reflexão acerca do ponto de vista dos nativos sobre o antropólogo que os visitava. Ele percebeu que era tratado todo o tempo como criança. Sua interpretação sugere que os Suyá o percebiam como uma criança porque ele não falava (a língua nativa); não sabia o que comer, nem tampouco como encontrar o que comer; não sabia caminhar pelas trilhas abertas na floresta; não fazia ideia de como dar conta de suas necessidades fisiológicas; e, sobretudo, perguntava o tempo todo. Logo: era uma criança. A reflexão nativa sobre o lugar social do antropólogo na aldeia era a deflagradora de um processo de socialização pautado na expectativa de ingenuidade do pesquisador. Por isso, Seeger foi deixado com as crianças.

Em minhas pesquisas em escolas, nunca fui confundido com crianças, mas fui visto como ingênuo. Essa percepção está associada à ideia de que somente os "nativos da escola" podem falar sobre a escola exatamente porque não são ingênuos. São resistências aos discursos externos, veiculados pelo Estado ou por especialistas em Educação que não se encontram na escola.

A crença em minha ingenuidade fez com que eu fosse convidado a responder questões que me localizassem nos espaços de pesquisa. Minha reputação transitou lentamente do "antropólogo" - que necessitava de muitas autorizações para realizar a pesquisa, passando para "o amigo do JP" - que já podia ser convidado a conhecer algumas escolas, caminhando para "o profissional”, que poderia falar de cultura nas escolas, chegando, finalmente, ao "Rodrigo".

Fui aceito no campo, mas esse reconhecimento trouxe outras implicações. Aproximei-me “dos nativos", e era necessário relativizá-los todo o tempo, além de controlar minhas reflexões sobre a inserção de projetos de orientação sexual na escola e objetivar as emoções presentes no processo de imersão etnográfica. Afinal, fiz muitos amigos e precisava lembrá-los de que eu estava fazendo pesquisa. Uma das profissionais de gestão com as quais convivi e que entrevistei, ao ser lembrada de que eu estava fazendo pesquisa, disse: "Tem problema, não! Você já é de casa”. 


\section{Ser de casa não é fácil!}

Depois que me transformei em uma pessoa de casa, fui recebido em todas as escolas em que desejei realizar trabalho de campo. Havia, inclusive, uma série de expectativas relacionadas à minha pessoa, que faziam com que algumas professoras dissessem: "Você é igualzinho ao que disseram", ou o contrário: "Você é muito diferente do que me falaram". Em ambos os casos, eu dizia: "É mesmo? E o que foi que falaram?" Nunca obtive respostas. Tratava-se de um conjunto de pequenos segredos guardados entre amigas.

Minha aceitação nos contextos escolares foi ampliada, mas não era possível permanecer invisível. Malinowski (1980) ensina que é importante observar os fatos no momento em que eles acontecem, porque as pessoas querem falar sobre eles; no caso das pesquisas urbanas e, mais especificamente, nas pesquisas realizadas em escolas, as pessoas não querem apenas falar sobre os eventos. Elas desejam que o observador fale e veicule uma opinião sobre o acontecido. As interações que estabeleci com professores, gestores e estudantes produziram situações em que eu era visto como um insider (Elias; Scotson, 2000; Becker, 2008), sempre convidado a assumir um dos lados do debate.

Durham (2004) problematiza a metodologia antropológica utilizada nas pesquisas urbanas. A autora indica que a tradição etnográfica tende a priorizar análises em que as culturas são vistas “de dentro”, com a ampla utilização da observação participante. A técnica, neste caso, prioriza a observação, de forma que a participação se consolida como condição necessária, mas não suficiente, para o trabalho de campo. 0 antropólogo observa mais do que participa, porque as distâncias entre pesquisador e objeto são bem delimitadas. Em uma situação de campo tradicional, embora o pesquisador conviva com os pesquisados, não deixa de ser estrangeiro, e a observação engloba a participação. Mas, quando se trata de antropologia urbana, as distâncias entre pesquisador e pesquisado são menores. Se o antropólogo é também nativo, as distâncias só são possíveis caso intencionalmente construídas; elas fazem parte do cabedal de recursos metodológicos inerentes à prática antropológica.

Ocorre, nesses casos, uma participação diferente, porque o pesquisador não precisa sair de casa para viver "na aldeia" com os nativos que estuda: a participação tende a englobar a observação. A descrição da posição ocupada ou construída pelo pesquisador no campo de pesquisa se consolida como condi- 
ção necessária para a análise, porque o antropólogo precisa inserir suas percepções subjetivas e narrá-las, como o faz com as observações realizadas. Narrar a participação é tão fundamental quanto narrar a observação. Passa-se, portanto, da "observação participante" para a "participação observante” (Durham, 2004, p. 369).

Ainda há um elemento que precisa ser considerado. Os “nativos urbanos” podem ser muito sedutores para os antropólogos. Wacquant (2002), após três anos de trabalho de campo em academias de boxe nos Estados Unidos, relata que passou por momentos em que o retorno para a vida acadêmica era percebido como frio e deprimente. Ele também utiliza a expressão “participações observantes”. A descrição apresentada em seguida resulta de um processo de pesquisa em que eu estava dentro e fora dos cursos de formação de professores e das salas de aula. De início, eu era um estranho, mas, aos poucos, fiquei conhecido.

\section{0 olhar antropológico sobre os projetos de orientação sexual}

Em 1997, o governo federal publicou os Parâmetros Curriculares Nacionais para o ensino das disciplinas da Educação Básica. A proposta trazia uma novidade: apresentadas como temas transversais, as questões relacionadas a saúde, meio ambiente, ética, orientação sexual e pluralidade cultural deveriam ser discutidas em todas as escolas de Ensino Fundamental no Brasil.

Após o primeiro contato com os temas transversais, decidi propor uma análise da implantação dessa proposta nas escolas de Ensino Fundamental. Optei por recortar a pesquisa, direcionando o foco para as classificações relacionadas a sexualidade, gênero e diversidade sexual, contidas no tema "orientação sexual".

O texto dos Parâmetros Curriculares Nacionais parte do pressuposto de que os professores estão formados e interessados em incluir os novos temas em suas aulas. Todavia, a Secretaria Municipal de Educação do Rio de Janeiro criou um curso de formação para professores, apresentado com a sigla POS (Programa de Orientação Sexual).

Meus interesses, de início, não estavam localizados nos cursos de formação. O objetivo era analisar o trabalho desenvolvido em sala de aula. Buscava acompanhar a utilização pedagógica de conceitos relacionados ao debate sobre gênero, sexualidade e diversidade. O foco estava direcionado para professores já formados e responsáveis por projetos de orientação sexual. 


\section{Um antropólogo em sala de aula}

Minha primeira entrevistada ${ }^{3}$ permitiu que eu observasse o projeto de orientação sexual coordenado por ela. Foi o primeiro momento em que pude mapear as representações e as classificações relacionadas a sexualidade, gênero e diversidade, além de compreender os cenários políticos apresentados e vividos pelos profissionais que desejam trabalhar com essas temáticas no cotidiano escolar.

O projeto era organizado em cinco encontros. Discutiam-se gênero, adolescência, sexualidade, doenças sexualmente transmissíveis e planejamento familiar. Em todas as aulas, a professora apresentava conceitos e oferecia informações para os estudantes, além de responder às questões colocadas pelos alunos. Uma descrição presente em meu caderno de campo permite compreender o desenvolvimento dessas atividades.

16 de outubro de 2001 - [...] os alunos receberam os panfletos do Nesa, “Programa de Orientação em Sexualidade e Prevenção às Doenças Sexualmente Transmissiveis e Aids", organizado pela UERJ. Ao receber o panfleto, uma menina perguntou: "Mas qual a qualidade das camisinhas distribuídas pelo serviço público?". 0 que levou a professora a defender os preservativos distribuídos pelo Ministério da Saúde, dizendo que são testados e comprovadamente de alta qualidade. Fez apenas uma pequena ressalva baseada no que chamou de "comportamento adolescente". As camisinhas têm validade de cinco anos, mas, no caso dos adolescentes devem ser usadas no máximo em três porque a "cultura adolescente", além de mexer o tempo todo, "leva a camisinha na bunda" - referia-se ao hábito de transportar a camisinha na carteira de dinheiro que fica, normalmente, no bolso traseiro das calças jeans. 0 problema era que a bunda era um "lugar quentinho" e o calor danificava a embalagem e o preservativo. Enquanto falava destes prazos de validade, um menino, rindo muito, exclamou: “Aaaa!!!! Vai comprar pra deixar guardada, é!", o que provocou muitos risos [...]. A primeira parte do encontro foi dedicada à apresentação de cada conceito presente no material entregue pela professora. Ela buscou a participação da turma lançando perguntas, inquirindo alunos individualmente e frisando a importância do entendimento dos conceitos para a vida dos estudantes. Na sequência, realizou um debate sobre vulnerabilidade e iniciou uma dinâmica sobre os nomes dos órgãos sexuais masculinos e femininos.

3. Professora de Biologia, coordenadora de Núcleo de Adolescentes Multiplicadores. 
Havia, nesses espaços, leituras específicas sobre o conceito de gênero e, principalmente, sobre igualdade de gênero. Os mundos masculino e feminino não eram contestados diretamente. 0 foco da crítica era a naturalização e a essencialização desses mundos. Como consequência lógica, a proposta política: que meninos e meninas, homens e mulheres experimentassem ambos os mundos. Igualdade de gênero aparecia como possibilidade de homens e mulheres romperem as fronteiras dos universos masculino e feminino.

A questão era mais complexa quando a temática transitava para diversidade sexual. Nesses momentos, as vivências não heterossexuais eram mais silenciadas do que discutidas. Os alunos escreviam sobre ser homem e ser mulher, mas sempre com base em uma perspectiva heterossexual. Quando eu indagava sobre esses silêncios, a professora e todos os outros professores entrevistados falavam sobre as dificuldades enfrentadas quando decidiam discutir o tema.

Ao final, o debate sobre diversidade sexual ficava reduzido à declaração pública do direito à liberdade ${ }^{4}$. Nas salas de aula, as discussões sobre sexualidade e gênero eram limitadas às construções do masculino e do feminino heterossexuais. Havia uma concepção específica de liberdade presente nessas aulas. Liberdade era poder ultrapassar as fronteiras de gênero, e os estudantes eram, inclusive, convidados a realizar essas experimentações com a utilização de brincadeiras. A professora enfatizava que homens e mulheres tinham os mesmos direitos, deveres e obrigações, e ambos poderiam realizar as tarefas socialmente estabelecidas para cada um dos gêneros.

\section{Um antropólogo em um curso de formação de orientadores sexuais}

Quando transitei para o doutorado, tinha informações sobre os cursos de capacitação, conhecia orientadores experientes, minhas observações etnográficas permitiam compreender a lógica dos projetos de orientação sexual, mas ainda precisava conhecer a formação dos orientadores. Eu desejava investigar, dentre outras questões, a formação teórica e prática necessária para que um docente fosse legitimado

4. As professoras, inclusive, citavam as dificuldades que enfrentavam, ao tentar compatibilizar a educação dos alunos com a educação dos filhos, especificamente os filhos homens. Elas desejavam que eles respeitassem a diversidade sexual, mas tinham que ser machões (Rosistolato, 2009). como professor de orientação sexual e a organização de um curso de formação.

Nos cursos, os docentes são tratados como discentes e convidados a participar da formação exatamente como seus alunos participariam, caso 
estivessem em seus lugares. A proposta é ensinar os professores a acessar "o emocional5" dos alunos. Para isso, eles precisam permitir que docentes veteranos os conduzam em direção ao seu próprio “emocional”. Esse processo de condução é intermediado pela troca de afetos e carinhos, além do incentivo às narrativas emocionais.

Os professores veteranos classificam o "emocional" como uma associação entre dois elementos interligados: autoestima e sentimentos. A teoria nativa explica que, “para aprender a 'se proteger", os estudantes precisam ter autoestima elevada. Também é necessário que entendam seus sentimentos e saibam como expressá-los, além de dominar os conhecimentos técnicos associados às doenças sexualmente transmissíveis, à AIDS e à reprodução humana. Uma descrição - também registrada em meu caderno de campo - permite compreender o trabalho de acesso ao emocional:

A coordenadora colocou uma música e pediu que todos dançassem em círculo. Enquanto o círculo se organizava, pediu que cada um colocasse a mão nos ombros da pessoa que estava à frente, "formando um trenzinho". Em seguida, a música foi interrompida e todos ficaram de cócoras, sem retirar as mãos dos ombros dos colegas. Em meio a gargalhadas e algumas quedas, os aprendizes cumpriram a missão. Sucessivamente, a música era desligada, todos ficavam de cócoras, levantavam e ficavam mais próximos da pessoa à frente, até que "o grupo" estava completamente junto. A coordenadora disse que teriam que abaixar ainda mais uma vez. Desconfiados, os aprendizes disseram que era impossível. "Não é não. Quando eu parar a música vocês têm que abaixar". Ao abaixar, perceberam que cada pessoa estava sentada no colo daquela que estava à sua retaguarda. Assim, era impossível continuar abaixando ou levantar. Ficaram todos "encaixados" uns nos outros. A coordenadora mandou que levantassem as mãos e disse "tá vendo gente, dá pra fazer. Basta confiar uns nos outros. Todo mundo consegue".

Após esse encontro, conversei com a coordenadora do curso e ela explicou que aquela dinâmica era fundamental para que o grupo fosse formado e conseguisse trabalhar em conjunto. Disse

5. Utilizo o termo "emocional" entre aspas porque faz parte das classificações utilizadas pelos formadores. Para o debate sobre o lugar deste termo na teoria nativa sobre orientação sexual na escola, ver Rosistolato (2011). 
que se tratava de um exercício de confiança em si mesmo e nos outros e, além disso, contribuía para que todos se sentissem mais à vontade.

Os cursos observados foram organizados com base nas mesmas temáticas desenvolvidas pelos professores em sala de aula: gênero, sexualidade, adolescência, diversidade sexual. A proposta metodológica para "acesso ao emocional" e a percepção de que as mudanças de comportamento dependem desse acesso também estavam presentes. Há consenso sobre a distribuição de informações e a capacidade dos alunos para buscá-las por si mesmos. 0 foco dos cursos, portanto, transita da informação para a sensibilização. Outra convergência está nos silêncios com relação à diversidade sexual. No curso de formação de professores, as diversidades foram apresentadas, mas o debate estava localizado nas dificuldades enfrentadas por sua presença em sala de aula e nos problemas trazidos pelo debate em torno dessas questões.

\section{Considerações finais}

A marca distintiva do trabalho de campo em Antropologia é a imersão nos contextos de interação vividos pelos sujeitos inseridos nas culturas que desejamos analisar. Não se trata, no entanto, de um mergulho às cegas. Durante toda a aventura antropológica, somos acompanhados pelas leituras e pelos problemas construídos previamente. Nosso contato com o campo ocorre intermeado por intenções que são discutidas, problematizadas, modificadas e revigoradas durante a pesquisa.

A Antropologia feita em escolas coloca o antropólogo em um jogo complexo de classificações e de identificações coletivas. É uma Antropologia feita com aqueles que estão perto e compartilham expectativas e classificações sobre as escolas e a educação escolar. Nesses espaços, o pesquisador é convidado a oferecer suas opiniões e, mesmo que não as ofereça, acaba por ser identificado com algumas posições presentes no campo.

As análises do desenvolvimento de projetos de orientação sexual e da formação de orientadores sexuais me permitiram mapear os diálogos entre a escola e outras instituições sociais. As políticas públicas educacionais são desenhadas com base em expectativas sobre os agentes sociais presentes nas escolas, mas esses mesmos agentes as reinterpretam durante os movimentos organizados para atendê-las.

O debate público sobre a orientação sexual na escola ativou conjuntos de classificações sociais sobre adolescência, juventude, sexualidade, gênero e diversidade 
sexual. Os professores, socialmente legitimados como portadores de conhecimento adequado para a orientação sexual dos estudantes, acabaram por desenvolver uma teoria própria sobre essa demanda social. Eles entenderam que os adolescentes estavam bem informados, mas mal formados. 0 único caminho para a formação era a sensibilização com foco na mudança de comportamento.

Seguindo essa teoria, os docentes apresentaram e discutiram os conceitos, mas procuraram, principalmente, sensibilizar os estudantes para que se percebessem como sujeitos independentes para lidar com a própria sexualidade, desde que optassem pelo sexo considerado mais seguro. Nesses caminhos, masculinidades, feminilidades e sexualidades foram problematizadas e as diversidades sexuais foram silenciadas. Assim, a escola consolidou seu lugar em espaços de diálogo que buscam definir modelos ideais de relação entre as adolescências e as sexualidades. 


\section{Referências bibliográficas}

BECKER, H. S. Outsiders. Estudos de sociologia do desvio. Rio de Janeiro: Zahar, 2008.

BRASIL. Secretaria de Educação Fundamental. Parâmetros Curriculares Nacionais: volume 10 - Pluralidade Cultural e Orientação Sexual. Brasília: MEC/SEF, 1997.

DAUSTER, T. Um outro olhar: entre a antropologia e a educação. Cadernos CEDES Centro de Estudos Educação e Sociedade, Unicamp, Campinas. [on-line]. v.18, n. 43, p.38-45, dez. 1997.

DURHAM, E. R. A dinâmica da cultura: ensaios de Antropologia. São Paulo: Cosac Naify, 2004. v. 1. 477p.

ELIAS, N.; SCOTSON, J. L. Os estabelecidos e os outsiders: sociologia das relações de poder a partir de uma pequena comunidade. Rio de Janeiro: Jorge Zahar, 2000.

GUSMÃO, N. M. M. Antropologia, estudos culturais e Educação: desafios da modernidade. Pro-Posições, v. 19, n. 3 (57), set./dez. 2008.

MALINOWSKI, B. Objeto, método e alcance desta pesquisa. In: GUIMARÃES, A. Z. (Org.). Desvendando máscaras sociais. São Paulo: Francisco Alves, 1980.

ROCHA, G.; TOSTA, S. P. Antropologia e Educação. Belo Horizonte: Autêntica, 2009.

ROSISTOLATO, R. Aprendendo "no emocional": uma teoria nativa sobre a relação dos adolescentes com a sexualidade. In: COELHO, M. C; REZENDE, C. B. (Org.). Cultura e sentimentos: ensaios em antropologia das emoções. 1. ed. Rio de Janeiro: Contra Capa; FAPERJ, 2011. v. 1, p. 197-215.

ROSISTOLATO, R. Gênero e cotidiano escolar: dilemas e perspectivas da intervenção escolar na socialização afetivo-sexual dos adolescentes. Revista Estudos Feministas - UFSC, Florianópolis, v. 7, p. 11-30, 2009. Impresso.

SEEGER, A. Os índios e nós: estudos sobre sociedades tribais brasileiras. Rio de Janeiro: Campus, 1980.

VELHO, G.; KUSCHNIR, K. (Org.). Pesquisas urbanas: desafios do trabalho antropológico. Rio de Janeiro: Jorge Zahar, 2003. 235 p.

WACQUANT, L. Corpo e alma: notas etnográficas de um aprendiz de boxe. Rio de Janeiro: Relume Dumará, 2002.

Submetido à publicação em 10 de janeiro de 2013.

Aprovado em o8 de março de 2013. 